\title{
Endocytic downregulation of ErbB receptors: mechanisms and relevance in cancer
}

\author{
Kirstine Roepstorff · Lene Grøvdal · Michael Grandal • \\ Mads Lerdrup · Bo van Deurs
}

Accepted: 6 February 2008 / Published online: 21 February 2008

(C) Springer-Verlag 2008

\begin{abstract}
ErbB receptors (EGFR (ErbB1), ErbB2, ErbB3, and ErbB4) are important regulators of normal growth and differentiation, and they are involved in the pathogenesis of cancer. Following ligand binding and receptor activation, EGFR is endocytosed and transported to lysosomes where the receptor is degraded. This downregulation of EGFR is a complex and tightly regulated process. The functions of ErbB2, ErbB3, and ErbB4 are also regulated by endocytosis to some extent, although the current knowledge of these processes is sparse. Impaired endocytic downregulation of signaling receptors is frequently associated with cancer, since it can lead to increased and uncontrolled receptor signaling. In this review we describe the current knowledge of ErbB receptor endocytic downregulation. In addition, we outline how ErbB receptors can escape endocytic downregulation in cancer, and we discuss how targeted anti-cancer therapy may induce endocytic downregulation of ErbB receptors.
\end{abstract}

Keywords Epidermal growth factor receptor . Endocytosis - Lysosomal degradation - ErbB2 . Ubiquitin $\cdot$ Endosomal sorting

\section{Introduction}

Proper endocytic uptake and endosomal sorting of signaling receptors are crucial mechanisms for the regulation of

K. Roepstorff · L. Grøvdal · M. Grandal · M. Lerdrup .

B. van Deurs $(\varangle)$

Department of Cellular and Molecular Medicine, the Panum Institute, University of Copenhagen, Blegdamsvej 3, 2200 Copenhagen N, Denmark e-mail: bvd@sund.ku.dk

K. Roepstorff

e-mail: kirroep@sund.ku.dk signaling activity involved in cellular growth, development, and differentiation (Crosetto et al. 2005; Fischer et al. 2006; Giebel and Wodarz 2006; Le Borgne 2006; Polo and Di Fiore 2006; Sorkin and von Zastrow 2002). This is not least true for the epidermal growth factor receptor (EGFR), a member of the ErbB family of receptor tyrosine kinases which contains four members: EGFR (ErbB1), ErbB2, ErbB3 and ErbB4. In addition to playing an important role in normal cellular functions, these receptors are involved in the pathogenesis of human cancers and receive much attention as targets for development of new anti-cancer drugs (Hynes and Lane 2005). There are several mechanisms whereby cancer cells can obtain uncontrolled ErbB receptor signaling, including increased receptor expression, activating mutations, and escape of endocytic receptor downregulation (Bache et al. 2004; Citri and Yarden 2006; Normanno et al. 2005; Polo et al. 2004; Warren and Landgraf 2006).

Our current understanding of endocytic downregulation of ErbB receptors is largely based on knowledge of EGFR behavior upon binding of epidermal growth factor (EGF) (Bache et al. 2004; Dikic 2003; Gruenberg and Stenmark 2004). EGFR is among the most well studied receptors, and it is regarded as a prototype of a signaling receptor that is internalized and degraded following ligand binding. In contrast, surprisingly little is known about endocytosis of ErbB2-4 as well as about EGFR endocytosis following binding of ligands other than EGF. However, it is becoming increasingly clear that the other ErbB receptors do not behave like EGFR regarding endocytosis. In this review we outline the molecular mechanisms of EGF-induced endocytic downregulation of EGFR. In addition, we describe the current knowledge of internalization and downregulation of the other ErbB receptors and discuss how the various ErbB ligands differ in their potential to induce receptor 
downregulation. Finally, we focus on internalization of these receptors as a promising target in anti-cancer therapy.

\section{The ErbB receptor system}

A thorough description of the structure and biological functions of the four ErbB receptors and their ligands is beyond the scope of this review and can be found elsewhere (Citri and Yarden 2006; Hynes and Lane 2005; Jones et al. 2006). In brief, the ErbB receptors are transmembrane receptor tyrosine kinases consisting of a glycosylated, extracellular $\mathrm{N}$-terminal part containing a ligand binding site and a dimerization arm, a transmembrane segment, and an intracellular part containing a tyrosine kinase domain and a C-terminal tail with several phosphorylation sites (Fig. 1) (Normanno et al. 2005). A large number of ErbB ligands

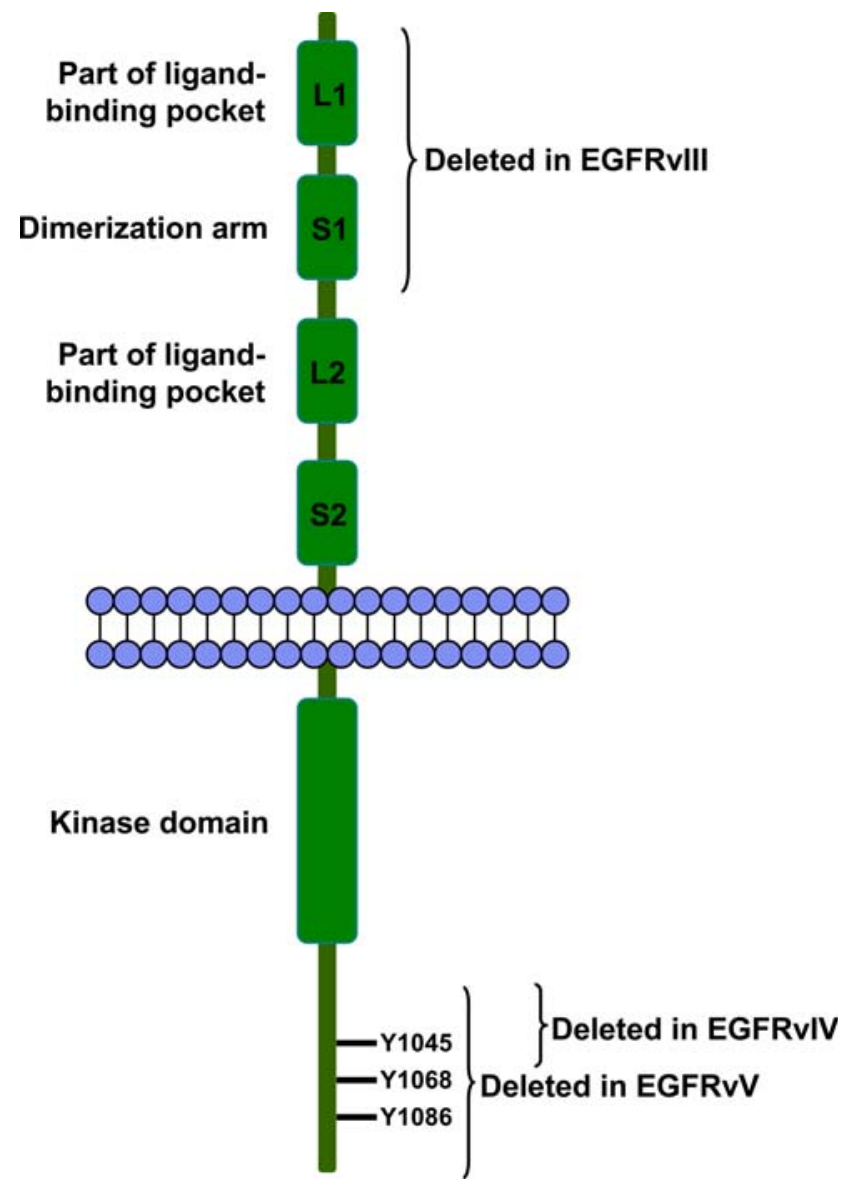

Fig. 1 Structure of EGFR. In the extracellular part of the receptor, EGFR harbours two domains (L1 and L2) that upon folding form the ligand-binding pocket. Between L1 and L2 is another domain (S1) that includes the dimerization arm. Intracellularly, EGFR has a kinase domain and a C-terminal tail with several amino acid residues that can be phosphorylated. The tyrosine residues $(\mathrm{Y})$ that are involved in $\mathrm{Cbl}$ binding are shown. The parts of wild-type EGFR that are deleted in EGFRvIII, EGFRvIV, and EGFRvV are indicated have been identified, some of which can bind to more than one of the ErbB receptors with high affinity (Table 1) (Breuleux 2007; Harris et al. 2003). The active, ligandbound ErbB receptors function as homo- or heterodimers, which can activate a multitude of signaling pathways involved in proliferation, differentiation, cell survival, and migration (Normanno et al. 2005).

\section{ErbB receptor activation}

The initial steps of ligand-mediated ErbB receptor activation have been well described upon solving the crystal structure of the EGFR extracellular domain bound to EGF (Garrett et al. 2002; Ogiso et al. 2002). EGF binding to EGFR has been proposed to induce a conformational change exposing the dimerization arm in the receptor extracellular domain (Burgess et al. 2003; Ferguson et al. 2003; Ogiso et al. 2002). Upon dimerization, the receptor's intrinsic kinase activity cross-phosphorylates specific residues in the C-terminal tail of the partnering receptor, allowing for the recruitment of phosphotyrosine-binding proteins to EGFR. ErbB3 and ErbB4 dimerize in response to ligand binding in a manner similar to EGFR, whereas ErbB2 differs from the other ErbB receptors by not binding to any ligand with high affinity (Bouyain et al. 2005; Burgess et al. 2003; Kani et al. 2005). Instead, ErbB2 is in a constitutively active conformation with an exposed dimerization arm even in the absence of ligand (Burgess et al. 2003). Its ability to homodimerize is limited due to the electronegativity of its extracellular part, but ErbB2 is the preferred

Table 1 ErbB receptors and their ligands

\begin{tabular}{lll}
\hline Receptor & Remarks & Ligands \\
\hline EGFR & & Epidermal growth \\
(ErbB1) & factor (EGF) \\
& & Transforming growth \\
& factor $\alpha$ (TGF $\alpha)$ \\
& Heparin-binding \\
& & EGF (HB-EGF) \\
& & $\beta$-Cellulin \\
& & Amphiregulin \\
& & Epiregulin \\
& & Epigen \\
ErbB2 & Constitutively exposed & \\
& dimerization arm & \\
ErbB3 & Hinase dead & Heregulin-1/Neuregulin-1 \\
& & Heregulin-2/Neuregulin-2 \\
ErbB4 & & Heregulin-1/Neuregulin-1 \\
& & Heregulin-2/Neuregulin-2 \\
& & Heregulin-3/Neuregulin-3 \\
& & Heregulin-4/Neuregulin-4 \\
& & Heparin-binding \\
& & EGF (HB-EGF) \\
& & $\beta$-Cellulin \\
& & Epiregulin \\
& &
\end{tabular}


heterodimerization partner for the other ErbB receptors (Garrett et al. 2003; Graus-Porta et al. 1997; Tzahar et al. 1996).

The signal transduction pathways activated by ErbB receptors include well-known signaling cascades such as the Ras-Erk1/2 pathway, the phospholipase $\mathrm{C} \gamma$-protein kinase C pathway, the phosphatidyl inositol 3 (PI 3)kinase-Akt pathway, and STAT signaling.

Endocytic downregulation of signaling receptors has for many years been regarded solely as a means of attenuating receptor signaling. However, during the last decade an increasing amount of evidence has suggested that some receptors, including EGFR, may continue their signaling activity from endocytic compartments and that the signaling occurring from here is qualitatively different from the signaling taking place at the plasma membrane (Miaczynska et al. 2004). Thus, ErbB receptor endocytosis is not merely a means of turning off activated receptors; it may also be a regulatory mechanism altering the signaling outcome.

\section{Endocytic downregulation of EGFR}

Regarding ligand-induced endocytic receptor downregulation, EGFR has been the most popular model system for many years, and the mechanisms of EGFR endocytosis and intracellular trafficking are therefore relatively well understood.

EGFR is activated upon EGF binding, leading to signaling and relocation to invaginating clathrin-coated pits (CCPs) on the plasma membrane. These pits give rise to clathrin-coated endocytic vesicles, and after the coat has been released from the membrane, the vesicles fuse with early endosomes and thereby deliver the receptor to this compartment. Here the receptor is sorted for further transport, either back to the cell surface by recycling, or to intraluminal vesicles (ILVs), a pathway that eventually leads to delivery of EGFR to lysosomes for degradation (Fig. 2). Some of these steps are now well established, but others remain elusive. Below we describe both what is known and what challenges we are facing in understanding the crucial pathway of clathrin-mediated EGFR endocytosis and endosomal sorting.

Sorting of EGFR to clathrin coated pits: ubiquitination or not?

One of the first steps in clathrin-mediated endocytic downregulation is the transport of cargo into CCPs. Despite the importance of regulating whether EGFR is endocytosed, the molecular machinery controlling this is poorly understood.

The constitutively endocytosed receptors, the transferrin receptor and the low-density lipoprotein receptor, are sorted into CCPs by interaction with the clathrin-binding AP-2 complex through conserved tyrosine-based motifs in the receptor's intracellular tail. EGFR also interacts with AP-2, indicating a similar role of AP-2 in EGFR endocytosis (Sorkin et al. 1995; Sorkin and Carpenter 1993). However, EGFR is not sorted into CCPs in its resting state, and the direct interaction of AP-2 with EGFR does not seem to be necessary for EGFR internalization (Nesterov et al. 1995). Thus, additional interaction partners in the CCPs are required for EGFR to be sorted into these plasma membrane microdomains. Since the kinase activity of EGFR has been shown to be important for this sorting (Lamaze and Schmid 1995), such interaction partners should bind modifications of EGFR that are only present in the activated state; e.g. phosphorylated residues and/or ubiquitinated residues.

Ubiquitination (Text box 1) has been known to mediate endocytosis of membrane receptors for vacuolar degradation in yeast (Hicke and Riezman 1996; Kolling and Hollenberg 1994), and ubiquitination has also been found to be involved in endocytic downregulation of mammalian receptors such as EGFR (reviewed in (Hicke 1999)). As a result, ubiquitination has long been considered a likely candidate as a CCP targeting signal at the plasma membrane.

Upon activation of EGFR, it is heavily ubiquitinated by the attachment of both monoubiquitin and polyubiquitin (Text box 1). As will be discussed below, this ubiquitination is a prerequisite for endosomal sorting of EGFR to ILVs in multivesicular bodies (MVBs), but its importance in the initial sorting to CCPs and internalization from the plasma membrane has been the subject of controversy for

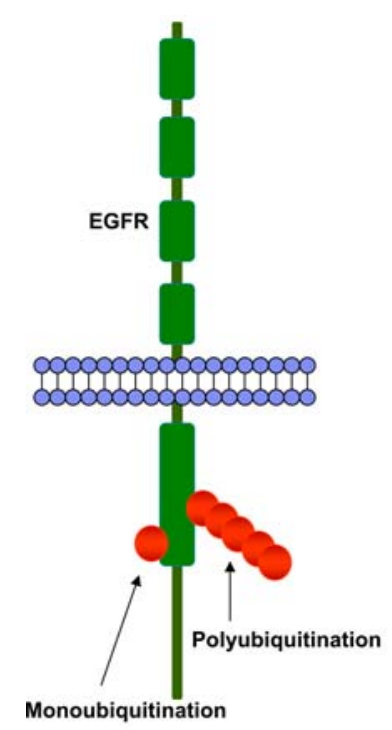

Text box 1 Ubiquitination

\begin{abstract}
Ubiquitin
Ubiquitin is a 76 amino acid peptide that can be covalently attached to lysine residues on receiver proteins via an isopeptide bond. This post-translational modification of proteins by ubiquitination has for a long time been recognized as a marker for degradation by proteasomes. In the recent years, it has become clear that ubiquitination is also important in other cellular processes, including endocytosis and lysosomal degradation. Ubiquitin can be covalently attached to other ubiquitin molecules via it's lysine residues, creating chains of ubiquitin called polyubiquitin. The EGFR is reported to be both monoubiquitinated and poly-ubiquitinated (Huang et al., 2006). The major ubiquitin lysines for formation of polyubiquitin is $\mathrm{K} 48$ and $\mathrm{K} 63$. Whereas ubiquitin chains formed via K48 are important for proteasomal degradation, K63-linked ubiquitination seems to be important for lysosomal targeting of plasma membrane receptors, and the polyubiquitination of EGFR is mostly in the form of K63-linked ubiquitin chains (Barriere 2007, Huang et al,. 2006)
\end{abstract}




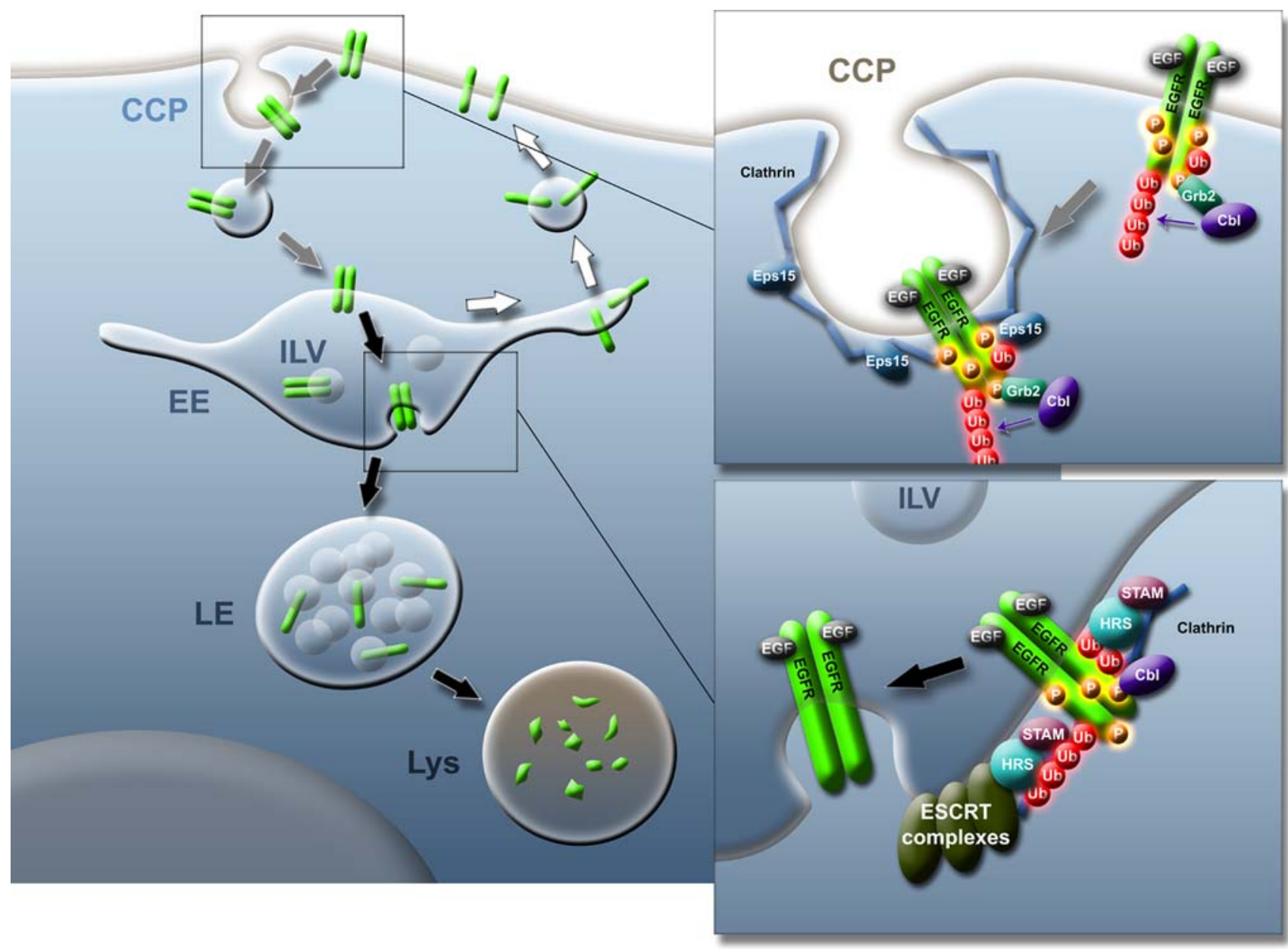

Fig. 2 Internalization and endosomal sorting of EGFR. Main figure: upon activation, EGFR (green) is translocated to clathrin coated pits (CCP) on the plasma membrane and internalized (grey arrows). After transport to early endosomes (EE), EGFR is either recycled back to the plasma membrane (white arrows) or taken up into intraluminal vesicles (ILVs). EE will mature to late endosomes (LE), and EGFR in ILVs will eventually be degraded in lysosomes (Lys) (black arrows). Upper insert at the plasma membrane, EGF-activated EGFR dimerize and the kinase activity of the receptors phosphorylates tyrosine residues $(\mathrm{P})$ in EGFR. This creates docking sites for intracellular proteins such as

some time. The ubiquitin ligase responsible for EGFR ubiquitination is $\mathrm{Cbl}$, a ring-finger domain E3 ubiquitin ligase (Levkowitz et al. 1999). Cbl is indeed necessary for EGFR endocytosis (Jiang and Sorkin 2003). Cbl can bind EGFR either directly by binding to phosphorylated Y1045, or indirectly via the adaptor protein Grb2, which binds to phosphorylated Y1068 and Y1086 (Fig. 1) (Levkowitz et al. 1999; Waterman et al. 2002). Binding of Cbl via phosphorylated Y1045 is not necessary for EGFR endocytosis, since the Y1045F EGFR mutant that cannot bind Cbl directly is internalized almost as efficiently as wild-type EGFR (Grøvdal et al. 2004; Jiang et al. 2003). In contrast, Cbl binding to EGFR via Grb2 is necessary for receptor internalization (Huang and Sorkin 2005). Thus, Grb2
Grb2. Grb2 mediates binding of the ubiquitin ligase $\mathrm{Cb}$ that adds mono- or polyubiquitins (Ub) to EGFR. Activated EGFR is transported to clathrin coated pits that in addition to clathrin also consists of Eps 15 and other proteins. Lower insert At the EE vacuolar membrane, EGFR destined for degradation still binds $\mathrm{Cbl}$ and is continuously phosphorylated and ubiquitinated. The EGFR ubiquitins are bound by Hrs that resides in at Hrs/STAM/clathrin coat, and this is followed by binding of ESCRT complexes to the ubiquitinated EGFR leading to uptake into ILVS

knockdown inhibits EGFR endocytosis, but a chimeric protein consisting of the Y1068/Y1086-binding domain of Grb2 fused to Cbl can rescue EGFR internalization in Grb2 depleted cells, showing that the prime role of Grb2 in EGFR internalization is recruitment of $\mathrm{Cbl}$ (Huang and Sorkin 2005).

Since functional $\mathrm{Cbl}$ is a prerequisite for EGFR internalization (Jiang and Sorkin 2003), and Cbl ubiquitinates EGFR (Levkowitz et al. 1998), it has long been assumed that Cbl-mediated ubiquitination of EGFR is the prime signal for EGFR translocation to CCPs. In accordance with this, overexpression of the $\mathrm{Cbl}$ mutant $70 \mathrm{Z}-\mathrm{Cbl}$ with impaired ubiquitin ligase activity inhibits EGFR internalization (Jiang and Sorkin 2003). To further investigate the 
role of EGFR ubiquitination in internalization, an EGFR mutated on 15 lysine residues was recently constructed. This mutant had an ubiquitination level corresponding to $1 \%$ of that seen for wild-type EGFR after EGF stimulation. Interestingly, the mutated EGFR still retained full kinase activity and displayed normal internalization (Huang et al. 2007). This could imply that EGFR ubiquitination is not a signal for internalization. Alternatively, the endocytic machinery recognizing ubiquitinated EGFR is highly sensitive, so that even a $1 \%$ residual ubiquitination is sufficient for proper targeting of EGFR to CCPs.

Importantly, $\mathrm{Cbl}$ may serve other functions in addition to ubiquitin ligase activity. It has been reported that $\mathrm{Cbl}$ binds endophilin via CIN85 (Soubeyran et al. 2002). Endophilin is a known regulator of clathrin-mediated endocytosis (Reutens and Begley 2002), and this recruitment of CIN85 and endophilin to EGFR by $\mathrm{Cbl}$ has been shown to be important for EGFR internalization (Soubeyran et al. 2002).

Although the role of EGFR ubiquitination as an internalization signal is controversial, several candidates, including Eps15, have been suggested as adaptors for sorting ubiquitinated EGFR into CCPs. Eps 15 is found in CCPs and has an ubiquitin-binding domain (Hawryluk et al. 2006; Stang et al. 2004). Furthermore, Eps 15 is recruited to the plasma membrane upon EGF stimulation of EGFR (Stang et al. 2004; Torrisi et al. 1999), and expression of dominant-negative Eps15 as well as siRNA-mediated knockdown of Eps15 has been shown to inhibit EGFR endocytosis (Bakowska et al. 2007; Benmerah et al. 1998; Fallon et al. 2006). Phosphorylation of Eps 15 has also been shown to be necessary for EGFR internalization (Confalonieri et al. 2000). However, a direct evidence of Eps 15 as an adaptor protein recognizing ubiquitinated EGFR via interactions with EGFR-attached ubiquitin has so far not been presented.

At present, it remains obscure which mechanisms are responsible for sorting of the activated EGFR to coated pits, although it is clear that $\mathrm{Cbl}$ and Grb2 are central, and Eps 15 may have important functions. One possible explanation for the apparent contradictory results regarding ubiquitin as an endocytic signal for EGFR is that it is not ubiquitination of EGFR itself but rather ubiquitination of accessory proteins by $\mathrm{Cbl}$ that is necessary for EGFR internalization.

Endosomal sorting of EGFR: a key role of ubiquitination

Upon internalization by clathrin-mediated endocytosis, EGFR is transported to early endosomes (Fig. 2). Both cargo destined for lysosomal degradation and for recycling back to the plasma membrane is delivered here, and the compartment is sometimes seen in the electron microscope as a vacuole with tubular elongations. The tubular elongated parts of the early endosomes are believed to be involved in recycling, whereas sorting for degradation initiates at the vacuolar membrane of the endosomes by inward budding, giving rise to ILVs containing membrane proteins destined for lysosomal degradation (Fig. 2). The internalized EGFR can be sorted both for recycling and for lysosomal degradation. Whereas recycling seems to be the default pathway from early endosomes, sorting for lysosomal degradation is mediated by Hrs/STAM and by the endosomal sorting complex required for transport (ESCRT) complexes (ESCRT-I to -III) that are believed to mediate receptor translocation into ILVs of MVBs (for recent review see (Williams and Urbe 2007)).

The EGF-activated EGFR is also associated with $\mathrm{Cbl}$ in early endosomes, resulting in continued ubiquitination of EGFR (Duan et al. 2003; Longva et al. 2002). Contrary to its uncertain role in receptor internalization (see above), ubiquitination has been convincingly demonstrated to be important for endosomal sorting of EGFR to lysosomes. EGFR mutated at intracellular lysine residues to give a receptor with decreased ubiquitination is severely degradation impaired following EGF stimulation (Huang 2006, 2007). Likewise, the Y1045F EGFR mutant that does not bind directly to $\mathrm{Cbl}$ and displays reduced ubiquitination is degradation impaired (Grøvdal et al. 2004; Jiang and Sorkin 2003; Levkowitz et al. 1999). This mutant does not translocate to ILVs (Grøvdal et al. 2004), giving further support to a model where ubiquitin is the signal for EGFR sorting for degradation.

Ubiquitin chains are recognized by ESCRT complexes, which retain ubiquitinated cargo in the membrane of early endosomes thereby hindering receptor recycling (Fig. 2) (Raiborg and Stenmark 2002). The first described point of recognition is Hrs and STAM, also known as the ESCRT-0 complex. On early endosomes, Hrs and clathrin form dynamic microdomains, which can be seen by EM as flat electron-dense areas on the limiting membrane (Raiborg et al. 2001; Sachse et al. 2002). Hrs and STAM interact with ubiquitinated cargo via their ubiquitin-interacting motif (UIM) domains. The proteins preferentially bind polyubiquitin (Polo et al. 2002), and the UIM of Hrs has recently been shown to bind two ubiquitin molecules simultaneously (Hirano et al. 2006). Conceivably, cargo must be either polyubiquitinated by K63-linked polyubiquitin chains or multiply monoubiquitinated for efficient sorting towards the lysosome for degradation (Barriere et al. 2007). This is in concordance with more than $50 \%$ of EGFR ubiquitination being in the form of poly-ubiquitin chains, primarily via K63 (Text box 1) (Huang et al. 2006).

After Hrs/STAM has retained ubiquitinated cargo within microdomains in the vacuolar membrane of the early endosome, ESCRT complexes (ESCRT-I-ESCRT-III) are 
sequentially recruited, eventually leading to sorting of EGFR into ILVs (reviewed in (Williams and Urbe 2007)). Recently, siRNA studies showed that knock-down of Hrs or ESCRT-I components caused increased recycling of EGFR. In contrast, knockdown of ESCRT-II and ESCRTIII components did not result in increased recycling of EGFR, but did impair degradation (Raiborg et al. 2007). This indicates that the fate of EGFR (recycling versus degradation) is determined upstream of ESCRT-II. ESCRT-II appears to be necessary for sorting of EGFR to ILVs. In contrast, the exact function of the ESCRT-III complex in EGFR sorting seems to be more complex. The original model was that ESCRT-III is important for formation of ILVs (Williams and Urbe 2007). However, it was recently reported that upon depletion of the ESCRT-III component VPS24, EGFR is still sorted into ILVs in MVBs and silenced (Bache et al. 2006). Thus the ESCRT-III complex might function downstream of internalization to ILVs, perhaps as late as in MVB fusion with lysosomes (Bache et al. 2006).

Differential effects of EGFR ligands on EGFR degradation

The model for EGFR sorting to lysosomes described above has been developed based on studies of EGF-stimulated cells. Six other ligands for EGFR have been described (Table 1), all of which play important roles both during embryogenesis and in adult life. In addition, EGFR ligands have been found in high concentrations in human cancers (Normanno et al. 2001; Normanno et al. 2005; Revillion et al. 2008). It is therefore important to establish whether the additional ligands have the same effects on EGFR downregulation as EGF. The only other EGFR ligand that has been well investigated with respect to EGFR trafficking is transforming growth factor $\alpha(\mathrm{TGF} \alpha)$. Whereas EGF targets EGFR to the degradative pathway, TGF $\alpha$ allows receptor recycling (Decker 1990). The differential intracellular sorting of EGFR after stimulation with TGF $\alpha$ compared to EGF is caused by differences in the pH-dependence of receptor-ligand binding. Whereas EGF binding to EGFR is relatively stable at the lower $\mathrm{pH}$ in endosomes, TGF $\alpha$ dissociates from the receptor at endosomal $\mathrm{pH}$ (Ebner and Derynck 1991). It is believed that continuous ligand binding is necessary for continuous ubiquitination and thereby for translocation of EGFR to the ILVs. In case of TGF $\alpha$, the ligand rapidly dissociates from the receptor in endosomes, leading to receptor dephosphorylation, de-ubiquitination, and recycling to the cell surface (Longva et al. 2002). Interestingly, this difference in their potential to induce EGFR degradation is thought to be the main reason why TGF $\alpha$ is a stronger mitogen than EGF (Waterman et al. 1998).

At present, the effects of heparin-binding EGF (HB$\mathrm{EGF}), \beta$-cellulin, Epiregulin, and Epigen on EGFR traffick- ing has not been investigated. A single study has investigated the effect of Amphiregulin on endocytic EGFR downregulation, and found that Amphiregulin failed to induce EGFR degradation. This was the case even in cells overexpressing $\mathrm{Cbl}$, although in these cells EGFR was highly ubiquitinated following Amphiregulin stimulation (Stern et al. 2007). Interestingly, this suggests that pronounced receptor ubiquitination is not sufficient to target receptors for lysosomal degradation. More studies are warranted to uncover how the remaining EGFR ligands affect receptor ubiquitination, endocytosis, and lysosomal degradation.

Clathrin-independent endocytic mechanisms involved in EGFR uptake

Although clathrin-dependent endocytosis is generally considered to be the major mechanism for internalization and downregulation of EGFR, other endocytic pathways have also been proposed during recent years, especially following stimulation with high concentrations of EGF (Sigismund et al. 2005). The concentration of EGF varies greatly throughout the human body. Thus, while the EGF concentration in tissue fluid is about $1-2 \mathrm{ng} / \mathrm{ml}$, it is much higher, up to $100 \mathrm{ng} / \mathrm{ml}$ or more, in tubular duct lumens of e.g., the kidney, salivary glands, and the mammary gland (Carpenter and Cohen 1979; Hayashi and Sakamoto 1988). Normally, EGFR is not reached by the high luminal concentrations of EGF in these systems, since the receptor is present at the basolateral site of the epithelial cells. However, during wound healing or malignant transformation the tight junctions disappear and allow the high concentrations of EGF to get access to the receptor (Mullin 2004). Very high EGF concentration can also be found in solid tumors (Salomon et al. 1995). It is therefore relevant to study whether the mechanisms of endocytic downregulation of EGFR are affected by the concentration of stimulating ligand.

Sigismund et al. (2005) have reported a role of caveolae in EGFR uptake. They found that at low concentrations of EGF (1-2 ng/ml), EGFR was not ubiquitinated and became internalized by clathrin-dependent endocytosis. In contrast, at high concentrations of EGF $(20 \mathrm{ng} / \mathrm{ml})$ the receptor became ubiquitinated and was to a high degree internalized by caveolae. This conclusion was based upon immunogold labeling electron microscopy showing that at $20 \mathrm{ng} / \mathrm{ml}$ of EGF, about half of the receptors were localized to caveolae and to caveolae-like structures or "caveosomes" apparently not connected to the plasma membrane (Sigismund et al. 2005). However, it is likely that such caveolae-like structures that appear to be freely located in the cytoplasm are actually surface-connected in another plane of sectioning (Sandvig et al. 2008). In another study, Orlichenko et al. (2006) showed that incubation of epithelial cells with 
$30 \mathrm{ng} / \mathrm{ml}$ of EGF for 5-20 min resulted in an eight to tenfold increase in the number of plasma membrane caveolae due to EGF-induced tyrosine phosphorylation of caveolin1. Moreover, live cell imaging revealed increased dynamics of green fluorescent protein (GFP)-tagged caveolin upon stimulation of cells with $30 \mathrm{ng} / \mathrm{ml} \mathrm{EGF}$. After 15-20 min of treatment, fluorescent caveolae were seen to move from the plasma membrane deeper into the cytoplasm (Orlichenko et al. 2006). Thus, some studies suggest a role of caveolae in EGFR endocytosis.

Caveolae are quite immobile under normal, nonstimulated conditions as revealed by FRAP (Fluorescence Recovery After Photobleaching) analysis of cells transfected with GFP-tagged caveolin and by other approaches (Hommelgaard et al. 2005; Kirkham et al. 2005; Thomsen et al. 2002). If caveolae were involved in EGFR-internalization stimulated by high concentrations of EGF to any significant degree, two possible mechanisms can be envisioned: either the EGFR-containing caveolae become internalized in a single-wave process, leading to depletion of the plasma membrane for caveolae as has been reported for SV40 virus (Pelkmans et al. 2001, 2002), or activation of EGFR stimulates an increased mobility or turnover of caveolae so that internalized caveolae become replaced by new caveolae at the plasma membrane. These scenarios have been tested by live cell imaging of cells expressing GFP- tagged caveolin (Kazazic et al. 2006). It was shown that even $100 \mathrm{ng} / \mathrm{ml}$ of EGF did not cause any wave of internalized caveolae from the plasma membrane, or any increased turnover of caveolae at the plasma membrane. Moreover, it was found that inhibition of clathrin-mediated endocytosis by siRNA against clathrin heavy chain strongly inhibited internalization of EGF both at 1 and $60 \mathrm{ng} / \mathrm{ml}$ EGF. It was therefore concluded that clathrin-dependent endocytosis is the major pathway for EGFR uptake also at high EGF concentrations, and that caveolae do not contribute significantly to endocytosis of EGFR at any EGF concentrations (Kazazic et al. 2006).

At high concentrations of EGF (100 ng/ml), induction of ruffling and macropinocytosis can be observed in some cells (Fig. 3, K. Roepstorff, unpublished observations). However, whether ligand and receptor internalization in this way leads to lysosomal degradation is uncertain. Furthermore, Orth et al. (2006) found that EGF $(30 \mathrm{ng} / \mathrm{ml})$ stimulated the formation of dorsal, circular waves which progressed inward and resulted in sequestration of about $50 \%$ of the activated EGFR from the plasma membrane. The process resulted in the formation of EGFR-positive tubular structures, and it was dependent on actin reorganization, receptor phosphorylation, PI 3-kinase activity, and dynamin 2. The functional consequences of the process remain to be determined, but the dorsal wave formation seems to be less frequent in tumor cells than in normal cells (Orth et al. 2006).

In conclusion, although alternative clathrin-independent mechanisms of EGFR endocytosis have been suggested, clathrin-mediated endocytosis still appear to be by far the most important mechanism for EGFR downregulation.

\section{Endocytic downregulation of ErbB2}

Interestingly, the behaviour of ErbB2 regarding endocytic downregulation differs significantly from that of EGFR, and it is generally accepted that ErbB2 avoids efficient endocytic downregulation (Austin et al. 2004; Baulida et al. 1996; Hommelgaard et al. 2004; Longva et al. 2005; Sorkin and Carpenter 1993; Wang et al. 1999).

Several studies have investigated why ErbB2 is less susceptible to endocytic downregulation than EGFR after activation, and two fundamentally different cellular mechanisms could explain this: inefficient internalization (Baulida et al. 1996; Hommelgaard et al. 2004; Lerdrup et al. 2006; Longva et al. 2005; Sorkin and Carpenter 1993; Wang et al. 1999), or efficient recycling of endocytosed ErbB2 back to the plasma membrane (Austin et al. 2004; Citri et al. 2003; Hendriks et al. 2003a, 2003b; Klapper et al. 2000; Lenferink et al. 1998; Yarden 2001). Using antibodies labeled with fluorophores or gold-particles to monitor ErbB2 trafficking, Austin and co-workers found that ErbB2 is constantly internalized and recycled (Austin et al. 2004). In contrast, two studies found no observable intracellular ErbB2 in unstimulated cells and that treatment with monensin, a compound known to inhibit recycling, led to very little intracellular accumulation of ErbB2 within two hours (Lerdrup et al. 2006; Longva et al. 2005). Importantly, immunogold labeling electron microscopy has demonstrated that ErbB2 is very infrequently found in clathrin coated pits: as little as 1 of 10,000 labeled ErbB2 molecules localize to these structures in unstimulated cells or in cells treated with ErbB ligands (Fig. 4a) (Hommelgaard et al. 2004). This suggests that the inefficient downregulation of ErbB2 is due to a low basal rate of internalization, although it is possible that ErbB2 could be taken up by clathrin independent endocytosis.

A chimeric EGFR where the C-terminal tail has been replaced by that of ErbB2 is as endocytosis impaired as a chimeric EGFR where the entire intracellular part has been replaced by that of ErbB2 (Sorkin and Carpenter 1993). This suggests that the C-terminal tail of ErbB2 is responsible for its endocytic impairment, and an interesting hypothesis is that this is caused by an inhibitory signal rather than a lack of endocytic stimuli (Sorkin and Carpenter 1993). This is supported by the lower stability and increased endocytic 

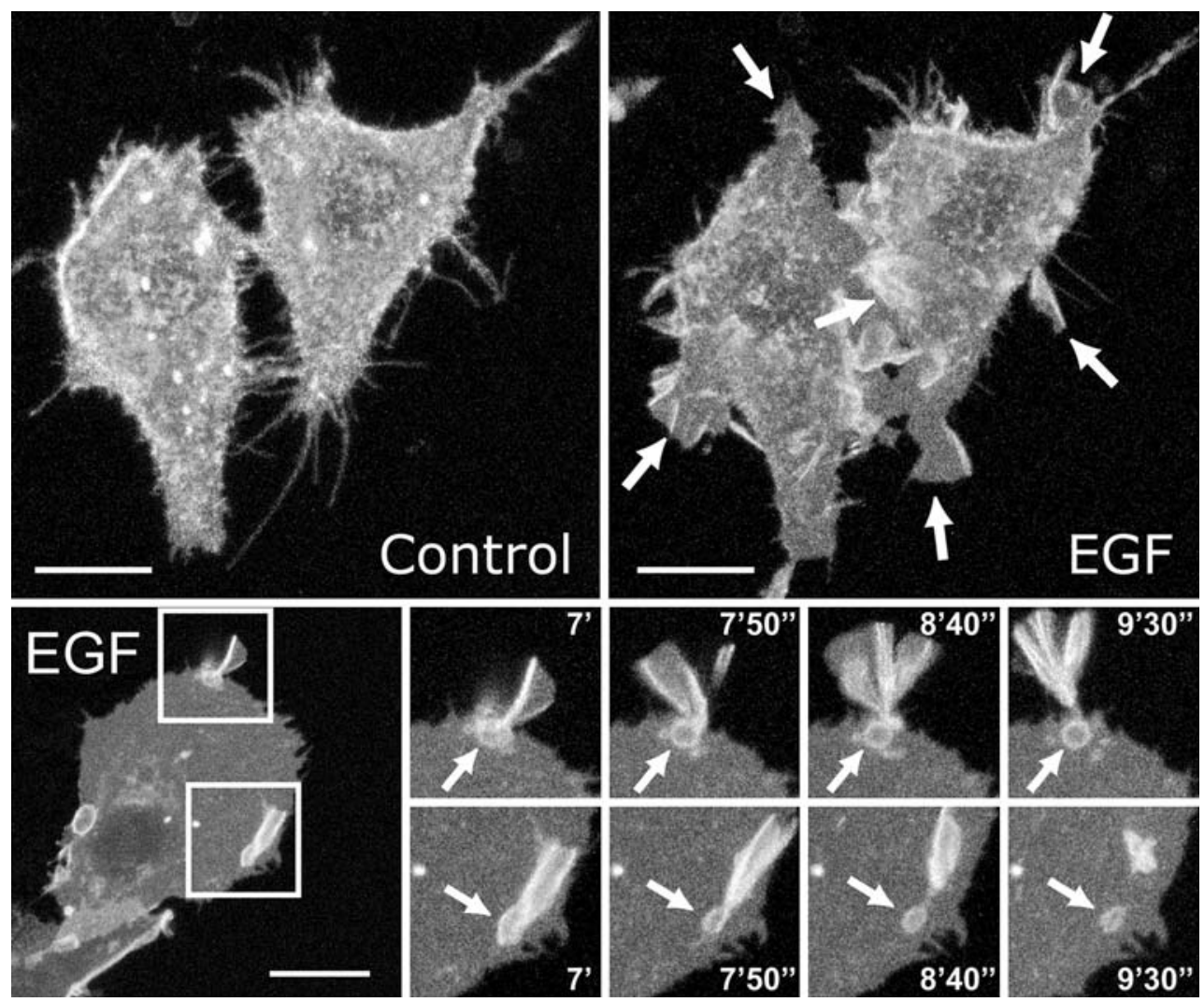

Fig. 3 EGF induces membrane ruffling and macropinocytosis. HEp2 cells expressing GPI-GFP as a marker of the plasma membrane were followed by $3 \mathrm{D}$ confocal microscopy over time. The upper panel shows two cells that were imaged before and 5 min after stimulation with $100 \mathrm{ng} / \mathrm{ml}$ EGF. Arrows indicate membrane ruffles formed after

EGF stimulation. The lower panel shows that ruffling leads to formation of macropinosomes (arrows). The large image to the left shows a cell $7 \mathrm{~min}$ after stimulation with $100 \mathrm{ng} / \mathrm{ml} \mathrm{EGF}$, and the small images show a time sequence during which macropinosomes are formed. Bars, $20 \mu \mathrm{m}$

downregulation of ErbB2 deletion mutants, which lack the C-terminal tail, compared to full-length ErbB2 (Lerdrup et al. 2007; Tikhomirov and Carpenter 2003). As mentioned previously, phosphorylation of EGFR on Y1045 is important for recruitment of $\mathrm{Cbl}$ and endocytic downregulation of EGFR. A Cbl docking site is also present in ErbB2 (Klapper et al. 2000; Levkowitz et al. 1999), and Cbl can be recruited to ErbB2 (Klapper et al. 2000; Levkowitz et al. 2000). However, the actual extent of $\mathrm{Cbl}$ binding is debated, and inefficient binding of $\mathrm{Cbl}$ could also explain the low lysosomal degradation of ErbB2 (Chan et al. 2004; Dankort et al. 1997; Levkowitz et al. 1996, 2000; Olayioye et al. 2000).

Several groups have reported that ErbB2 can transfer its endocytic reluctance to EGFR, since ErbB2 overexpression protects EGFR from endocytic downregulation and can increase EGFR levels (Haslekas et al. 2005; Muthuswamy et al. 1999; Wang et al. 1999; Worthylake et al. 1999). However, the studies do not reach similar conclusions regarding the underlying mechanism, and different models have been presented including lack of $\mathrm{Cbl}$ recruitment to activated EGFR (Muthuswamy et al. 1999), inhibited for- mation of clathrin coated pits after EGFR stimulation (Haslekas et al. 2005), or reduced targeting of internalized EGFR to lysosomes (Worthylake et al. 1999).

Although it is well established that ErbB2 is severely endocytosis impaired compared to EGFR, there is currently no consensus model of how this is achieved. Taking into account the major focus that ErbB2 receive as an oncogene and as a drug target, a better understanding of the mechanisms hindering ErbB2 endocytosis and lysosomal degradation is warranted.

\section{Endocytic downregulation of ErbB3 and ErbB4}

At present, remarkably little is known about endocytosis of ErbB3 and ErbB4. In the first studies of their endocytosis, ErbB3 and ErbB4 were reported to be internalization impaired to the same extent as ErbB2 (Baulida et al. 1996). In accordance with this, the ErbB3- and ErbB4-specific ligand Heregulin $1 \beta$ was found to be internalized less efficient and much slower than the EGFR-specific ligand EGF, supporting that ErbB3 and ErbB4 are not endocyto- 


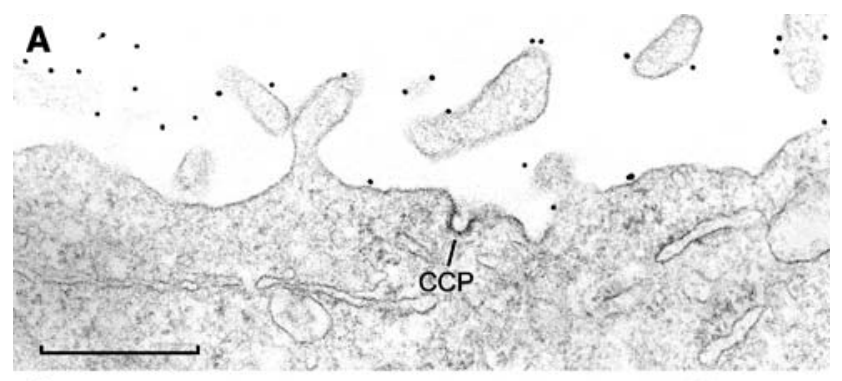

B

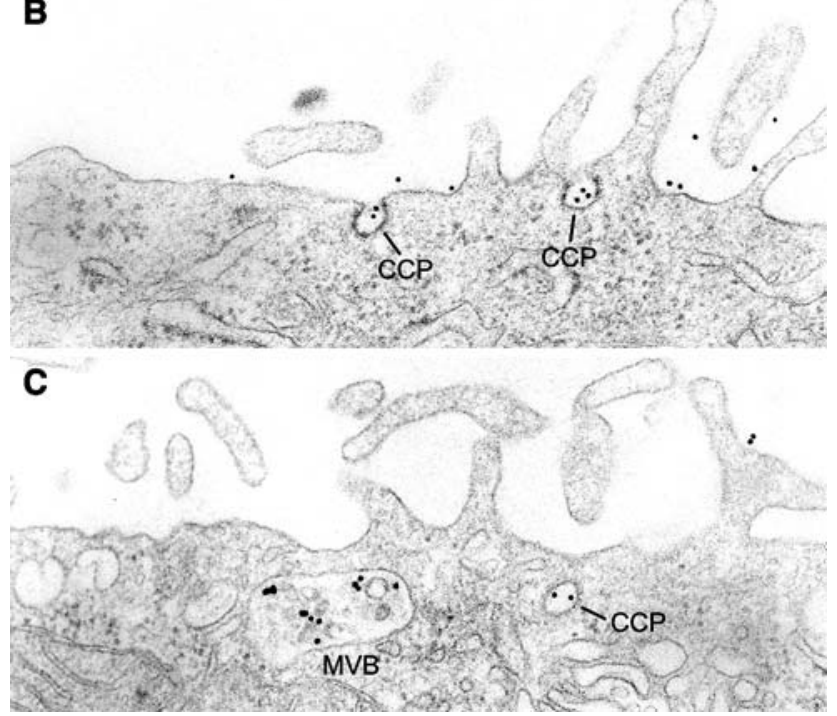

Fig. 4 Crosslinking of ErbB2 induces receptor internalization. a Fixed SK-BR-3 breast cancer cells have been incubated with a mouse monoclonal antibody against the extracellular $\mathrm{N}$-terminal part of ErbB2, and subsequently with a gold-conjugated anti-mouse antibody. Thereafter the cells were embedded in Epon, sectioned and examined in the electron microscope. It is seen that ErbB2 is mainly associated with membrane protrusions. An empty clathrin-coated pit (CCP) is also seen. b, c SK-BR-3 cells have been incubated for $1 \mathrm{~h}$ at $37^{\circ} \mathrm{C}$ with the anti-ErbB 2 antibody followed by the gold-conjugated antibody before fixation and embedding. Note how the antibody crosslinking drives ErbB2 down from the protrusions to the bulk membrane, where it is seen in clathrin-coated pits (CCP). Labeling of a multivesicular body (MVB) is also seen in $\mathbf{c}$, showing that crosslinked ErbB2 is internalized. For details see (Hommelgaard et al. 2004). Bar $0.5 \mu \mathrm{m}$

sed as efficiently as EGFR (Baulida and Carpenter 1997; Waterman et al. 1998). Interestingly, the endocytic impairment of ErbB3 could be transferred to EGFR by replacing the EGFR C-terminal tail with the ErbB3 C-terminal tail, suggesting that there are regions in the $\mathrm{C}$-terminus of ErbB3 that protect the receptor against internalization (Waterman et al. 1999).

Whereas the abovementioned studies suggest that ErbB3 and ErbB4 are endocytosis impaired, both of the receptors can be ubiquitinated (Cao et al. 2007; Omerovic et al. 2007; Qiu and Goldberg 2002). In case of ErbB3, heregulin1 $\beta$ stimulation leads to ubiquitination of the receptor by the ubiquitin ligase Nrdp1. Knockdown of Nrdp1 increases the steady-state levels of ErbB3, suggesting that Nrdp1-mediated ubiquitination may target ErbB3 to degradation (Qiu and Goldberg 2002). ErbB4 is ubiquitinated by the ubiquitin ligase Itch, which induces increased degradation of ErbB4 when overexpressed (Omerovic et al. 2007). The ubiquitination-stimulated degradation of both ErbB3 and ErbB4 depends upon proteasomal activity (Cao et al. 2007; Omerovic et al. 2007; Qiu and Goldberg 2002). Interestingly, the degradation appears to involve lysosomes as well, since inhibition of lysosomal function retards the degradation of both ErbB3 and ErbB4 (Cao et al. 2007; Omerovic et al. 2007). This apparent need for both lysosomes and proteasomes for receptor degradation may appear as a paradox, but it has been shown that proteasomal activity is required for lysosomal degradation of EGFR as well (Alwan et al. 2003; Longva et al. 2002). Thus, if this is also the case for ErbB3 and ErbB4, the block of receptor degradation seen after proteasomal inhibition could be due to an effect on lysosomal function like the one observed for EGFR. Obviously, this is in discrepancy with the studies reporting that neither ErbB3 nor ErbB4 becomes efficiently endocytosed, and more studies are therefore warranted addressing the role of endocytosis and lysosomal degradation of ErbB3 and ErbB4, not least in cancer cells.

\section{Escape of endocytic downregulation in cancer}

Several EGFR mutants have been found in tumors indicating an oncogenic role of these mutants. The mutations can be in the form of small or large deletions, point mutations, or amplifications and these alterations can be found both in the intra- and extracellular parts of EGFR (Fig. 1). Whether the mutations are the cause of or a result of transformation is often not clear, but some EGFR mutants show increased signaling, which will contribute to oncogenesis. The increased signaling can be the result of constitutive activation and/or impaired downregulation. In this review we will focus on examples of EGFR mutants with impaired downregulation.

Proper association of the activated receptor with the downregulation machinery is essential for stopping the signaling of EGFR. As described above, binding of the ubiquitin ligase $\mathrm{Cbl}$ to EGFR is central in the downregulation. EGFRvIV and EGFRvV are both found in glioblastomas (Frederick et al. 2000; Peschard and Park 2003; Zandi et al. 2007). Due to intracellular deletions, these mutants lack the direct binding site of $\mathrm{Cbl}$ and in addition EGFRvV also lacks the indirect Grb2-mediated binding sites (Frederick et al. 2000; Peschard and Park 2003; Zandi et al. 2007). The viral oncogene v-ErbB resembles EGFR, but lacks certain parts including the direct binding site of $\mathrm{Cbl}$ (Peschard and Park 2003; Zandi et al. 2007). The downregulation of EGFRvIV, EGFRvV and v-ErbB has not been investigated, but they would be expected to have an impaired downregulation. 
The best characterized EGFR mutant with impaired downregulation is EGFRvIII. Initially found in glioblastomas (Sugawa et al. 1990), EGFRvIII has later been found in a range of other types of tumors (Garcia de Palazzo et al. 1993; Ge et al. 2002; Moscatello et al. 1995; Okamoto et al. 2003; Olapade-Olaopa et al. 2000). In concordance with this, EGFRvIII can transform fibroblasts and the receptor enhances proliferation and/or tumorigenicity of cells both in vivo and in vitro (Batra et al. 1995; Moscatello et al. 1995; Nagane et al. 1996; Nishikawa et al. 1994; Pedersen et al. 2005a, 2005b; Tang et al. 2000). EGFRvIII is characterized by a deletion of amino acid residues 6-273 found in the extracellular part of EGFR. This gives a truncated $145 \mathrm{kDa}$ receptor with a non-functional ligand binding pocket and no dimerization arm. Thus, EGFRvIII is incapable of binding any ligands; the receptor is however constitutively active (Kuan et al. 2001), and it activates Ras-Erk1/2 and PI 3-kinase-Akt (Antonyak et al. 1998; Chu et al. 1997; Montgomery et al. 1995; Moscatello et al. 1996, 1998). The constitutive activity may be sufficient for tumorigenicity, but impaired downregulation would enhance the effect. EGFRvIII can associate with overexpressed $\mathrm{Cbl}$ and this leads to downregulation (Davies et al. 2006). However, two recent reports show that EGFRvIII is not degraded in cells with endogenous levels of $\mathrm{Cbl}$, and that this can be due to virtually no phosphorylation of Y1045 (Grandal et al. 2007; Han et al. 2006). In concordance with the hypophosphorylation at the direct binding site Y1045, Cbl binds primarily through the adaptor protein Grb2 (Grandal et al. 2007). This gives no detectable ubiquitination, and instead of being degraded, internalized EGFRvIII is recycled back to the plasma membrane (Grandal et al. 2007). Thus, as seen for the Y1045F EGFR mutant, direct binding of $\mathrm{Cbl}$ to the receptor appears to be necessary for efficient degradation.

In conclusion, endocytic impairment may be a returning theme of oncogenic EGFR mutants. ErbB signaling can also be sustained if the molecular machinery normally involved in receptor downregulation does not function optimally. Indeed, several mutations of such proteins have been found in tumors, including Cbl, TSG101 (an ESCRT-I subunit), and VPS25 (an ESCRT-II subunit) (recently reviewed in (Haglund et al. 2007)).

\section{Endocytic downregulation of ErbB receptors as a therapeutic target in cancer treatment}

Since lack of endocytic downregulation is an emerging theme in ErbB cancer biology, it is evident that stimulation of ErbB endocytosis and lysosomal degradation is an attractive means to inhibit tumor growth.
Antibody-mediated crosslinking can induce internalization of ErbB receptors

From a therapeutic perspective, an appealing way to induce endocytic downregulation of ErbB receptors is by antibody-mediated crosslinking. Indeed, an efficient way to induce endocytosis of both EGFR and ErbB2 is crosslinking with polyvalent antibody conjugates (Fig. 4 b, c) (Friedman et al. 2005; Hommelgaard et al. 2004). The most studied ErbB2 antibody with an anti-tumor potential is Trastuzumab, which is currently used in the treatment of breast cancer (Hudis 2007). Although the dominating opinion has been that Trastuzumab causes endocytic downregulation of ErbB2 (Menard et al. 2003; Rubin and Yarden 2001; Yarden 2001), several recent studies suggest that Trastuzumab does not induce endocytosis of ErbB2 to a significant degree (Austin et al. 2004; Hommelgaard et al. 2004; Longva et al. 2005).

Cetuximab is an antibody targeting EGFR that is currently used in treatment of colorectal cancer and head and neck cancer (Harari et al. 2007). Several studies have shown that Cetuximab induces internalization of EGFR (Jaramillo et al. 2006; Sunada et al. 1986). In contrast to ligand-induced endocytosis, Cetuximab-induced EGFR internalization is independent of receptor tyrosine kinase activity, and it is both slower and less efficient in terms of receptor downregulation than the ligand-induced endocytosis (Jaramillo et al. 2006).

At present, the knowledge of mechanisms underlying antibody-mediated endocytic downregulation is relatively sparse. It is clear that the endocytic potential of antibodies vary, but the reason for this remains elusive. Furthermore, it is debated whether the endocytic potential of antibodies is correlated to their anti-tumor potential (Hurwitz et al. 1995; Klapper et al. 1997; Park et al. 1999). Indeed, in cases where the anti-tumor effect of therapeutic antibodies is in part due to antibody-dependent activation of an immune response, internalization of bound antibodies will be a therapeutic disadvantage, since it will clear the surface for antibodies that will otherwise be recognized by immune cells such as natural killer cells. However, antibody-mediated receptor endocytosis followed by degradation may be advantageous in the treatment of tumors that rely heavily upon ErbB receptor signaling as a growth-promoting signal.

A useful observation is that extensive antibody-based crosslinking of ErbB receptors is far more efficient at inducing ErbB endocytic downregulation than single antibodies are (Friedman et al. 2005; Hommelgaard et al. 2004). Crosslinking can either be done using antibodies that forms multivalent aggregates via secondary antibodies or gold particles (Hommelgaard et al. 2004) or by a more clinically relevant approach using combinations of monoclonal antibodies against distinct epitopes in an ErbB recep- 
tor (Friedman et al. 2005). Thus, whereas administration of Trastuzumab alone did not induce significant ErbB2 endocytosis, the combination of Trastuzumab with another monoclonal antibody to ErbB2 was very efficient at downregulating ErbB2. In addition, the combination of two antibodies was much more efficient at inhibiting tumor growth in a mouse model compared to Trastuzumab administered alone (Friedman et al. 2005).

Hsp90 inhibition stimulates ErbB2 cleavage and internalization

Another efficient way to induce endocytosis and lysosomal degradation of ErbB2 is inhibition of the chaperone HSP90. HSP90 has gained a lot of attention due to the involvement of many of its clients in cancers, and several inhibitors are being tested in clinical trials, including the Geldanamycin derivative 17-AAG (Goetz et al. 2003; Solit and Chiosis 2008; Vastag 2006; Whitesell and Lindquist 2005). ErbB2 is one of the most prominent client proteins of the chaperone HSP90 (Citri and Yarden 2006; Linggi and Carpenter 2006), and this interaction is considered as a potentially valuable pharmacological target (Citri et al. 2004; Marmor et al. 2004; Neckers 2002; Neckers and Ivy 2003). ErbB2 overexpressing cancer cells often binds 17-AAG with an even higher affinity than other cancers cells, suggesting that ErbB2 overexpressing cells are highly dependent on HSP90 activity (Kamal et al. 2003). Inhibition of HSP90, e.g. by using Geldanamycin, leads to recruitment of the cochaperone and ubiquitin ligase CHIP to ErbB2 and ubiquitination of the receptor (Xu et al. 2002; Zhou et al. 2003).

Several degradation mechanisms are involved in ErbB2 downregulation following its ubiquitination. Mimnaugh and coworkers (Mimnaugh et al. 1996) found that HSP90inhibition led to degradation of ErbB2 in a proteasomedependent manner, and this has been interpreted as if degradation of the transmembrane ErbB2 was carried out by the proteasome (Citri et al. 2002; Hong et al. 1999; Way et al. 2004; Xu et al. 2001; Zheng et al. 2000). However, later studies found that ErbB2 is endocytosed and degraded in lysosomes after Geldanamycin stimulation (Fig. 5 a) (Austin et al. 2004; Lerdrup et al. 2006; Longva et al. 2005; Tikhomirov and Carpenter 2000), and that the proteasomal activity is actually needed for endocytosis and lysosomal degradation of ErbB2 after Geldanamycin stimulation (Lerdrup et al. 2006). Finally, Tikhomirov and Carpenter have demonstrated that the C-terminus of ErbB2 is cleaved by endoproteases into a transmembrane p135 and several cytosolic fragments in response to Geldanamycin-treatment (Tikhomirov and Carpenter 2000, 2001, 2003). Recent work from our group showed that this cleavage also promotes endocytosis and lysosomal degradation of ErbB2 (Lerdrup et al. 2007). Using a doubly fluorescent ErbB2
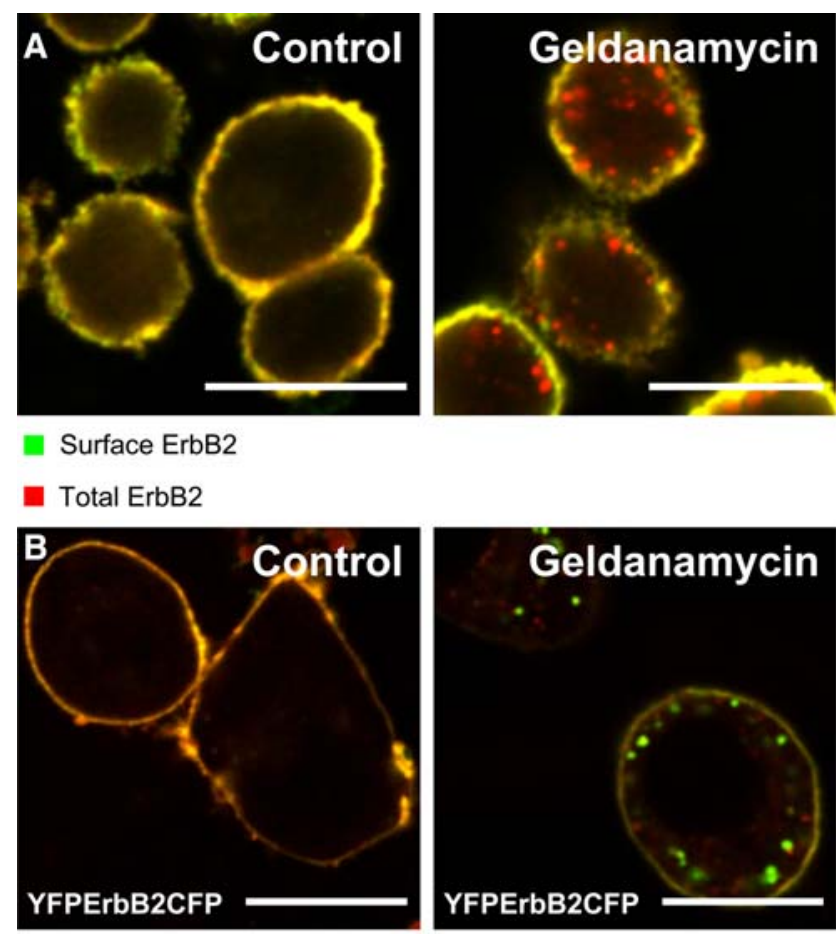

YFP (Extracellular part)

- CFP (Intracellular part)

Fig. 5 HSP90 inhibition stimulates ErbB2 cleavage and internalization. a ErbB2 is internalized after $2 \mathrm{~h}$ of Geldanamycin-stimulation $(3 \mu \mathrm{M})$ of SK-BR-3 breast cancer cells. Sequential immunocytochemistry was used to distinguish between internalized and surface associated ErbB2. Fixed cells were stained with antibodies against ErbB2 before permeabilization (green). After permeabilization, cells were once again stained with antibodies against ErbB2 (red). Only the latter antibody staining (red) gain access to intracellular ErbB2, which therefore appears red whereas surface ErbB2 is stained both red and green and therefore appears yellow. For details see (Lerdrup et al. 2006). b YFP-ErbB2-CFP is cleaved after $2 \mathrm{~h}$ of Geldanamycin-stimulation of SK-BR-3 cells. A construct with YFP fused to the extracellular N-terminus and CFP fused to the intracellular C-terminus of ErbB2 was expressed in SK-BR-3 cells for $48 \mathrm{~h}$ and followed by incubation with $0.3 \mu \mathrm{M}$ Geldanamycin for $2 \mathrm{~h}$ as indicated. YFP-ErbB2-CFP where the C-terminal tail has been cleaved off appears green. Note the increased amount of such cleavage in vesicles compared to the plasma membrane after Geldanamycin stimulation. For details see (Lerdrup et al. 2007). Bars $20 \mu \mathrm{m}$

tagged with yellow fluorescent protein (YFP) and cyan fluorescent protein (CFP) in each terminus, we found that ErbB2 was cleaved at the plasma membrane after Geldanamycin stimulation. C-terminally cleaved ErbB2 as well as an ErbB2 deletion mutant lacking its C-terminal tail were endocytosed and degraded in lysosomes far more efficiently than full length ErbB2 (Fig. 5b) (Lerdrup et al. 2007).

As opposed to ErbB2, wild-type EGFR is relatively insensitive to Hsp90 inhibition. However, the Geldanamycin derivative 17-AAG stimulates degradation of constitutively active EGFR mutants commonly found in lung cancer (Sawai et al. 2008). Whether 17-AAG induces deg- 
radation of mutant EGFRs by stimulating endocytosis and lysosomal degradation remains to be determined.

\section{Perspectives}

In spite of its crucial importance both in health and disease, the ErbB receptor system still has hidden secrets regarding its regulation. It is evident that we need to know much more about the molecular mechanisms underlying endocytic downregulation of the otherwise heavily investigated ErbB receptors. One important area that deserves future attention is further mapping of the mechanisms responsible for recruitment of EGFR to CCPs. Moreover, EGFR endocytosis does not seem to be representative of the other ErbB receptor family members, which all appear to be endocytosis impaired to some extent compared to EGFR. It is especially of interest to decipher how formation of heterodimers between the different ErbB receptors affects their endocytic downregulation. In addition, the large number of ErbB ligands adds further complexity to the system, since they may vary in the capability to stimulate endocytosis and lysosomal degradation of their receptors. Interestingly, the few ligands that have been investigated so far differ significantly in their ability to induce endocytic downregulation of ErbB receptors.

More insight into endocytic downregulation of ErbB receptors is indeed relevant for understanding the role of these receptors in cancer, and it could lead to identification of novel targets for cancer therapy directed at downregulating signaling receptors. Although still in the making, the clinical as well as preclinical results show that targeted therapy stimulating endocytic downregulating of ErbB receptors is a promising tool in cancer treatment.

\section{References}

Alwan HA, van Zoelen EJ, van Leeuwen JE (2003) Ligand-induced lysosomal epidermal growth factor receptor (EGFR) degradation is preceded by proteasome-dependent EGFR de-ubiquitination. J Biol Chem 278:35781-35790

Antonyak MA, Moscatello DK, Wong AJ (1998) Constitutive activation of c-Jun N-terminal kinase by a mutant epidermal growth factor receptor. J Biol Chem 273:2817-2822

Austin CD, De Maziere AM, Pisacane PI, van Dijk SM, Eigenbrot C, Sliwkowski MX, Klumperman J, Scheller RH (2004) Endocytosis and sorting of ErbB2 and the site of action of cancer therapeutics trastuzumab and geldanamycin. Mol Biol Cell 15:52685282

Bache KG, Slagsvold T, Stenmark H (2004) Defective downregulation of receptor tyrosine kinases in cancer. EMBO J 23:2707-2712

Bache KG, Stuffers S, Malerød L, Slagsvold T, Raiborg C, Lechardeur D, Walchli S, Lukacs GL, Brech A, Stenmark H (2006) The ESCRT-III subunit hVps24 is required for degradation but not silencing of the epidermal growth factor receptor. Mol Biol Cell $17: 2513-2523$
Bakowska JC, Jupille H, Fatheddin P, Puertollano R, Blackstone C (2007) Troyer syndrome protein spartin is mono-ubiquitinated and functions in EGF receptor trafficking. Mol Biol Cell 18:1683-1692

Barriere H, Nemes C, Du K, Lukacs GL (2007) Plasticity of polyubiquitin recognition as lysosomal targeting signals by the endosomal sorting machinery. Mol Biol Cell 18:3952-3965

Batra S, Castelino-Prabhu S, Wikstrand C, Zhu X, Humphrey P, Friedman H, Bigner D (1995) Epidermal growth factor ligand-independent, unregulated, cell-transforming potential of a naturally occurring human mutant EGFRvIII gene. Cell Growth Differ 6:1251-1259

Baulida J, Carpenter G (1997) Heregulin degradation in the absence of rapid receptor-mediated internalization. Exp Cell Res 232:167172

Baulida J, Kraus MH, Alimandi M, Di Fiore PP, Carpenter G (1996) All ErbB receptors other than the epidermal growth factor receptor are endocytosis impaired. J Biol Chem 271:5251-5257

Benmerah A, Lamaze C, Begue B, Schmid SL, Dautry-Varsat A, CerfBensussan N (1998) AP-2/Eps15 interaction is required for receptor-mediated endocytosis. J Cell Biol 140:1055-1062

Bouyain S, Longo PA, Li S, Ferguson KM, Leahy DJ (2005) The extracellular region of ErbB4 adopts a tethered conformation in the absence of ligand. Proc Natl Acad Sci USA 102:15024-15029

Breuleux M (2007) Role of heregulin in human cancer. Cell Mol Life Sci 64:2358-2377

Burgess AW, Cho HS, Eigenbrot C, Ferguson KM, Garrett TP, Leahy DJ, Lemmon MA, Sliwkowski MX, Ward CW, Yokoyama S (2003) An open-and-shut case? Recent insights into the activation of EGF/ErbB receptors. Mol Cell 12:541-552

Cao Z, Wu X, Yen L, Sweeney C, Carraway III KL (2007) Neuregulininduced ErbB3 downregulation is mediated by a protein stability cascade involving the E3 ubiquitin ligase Nrdp1. Mol Cell Biol 27:2180-2188

Carpenter G, Cohen S (1979) Epidermal growth factor. Annu Rev Biochem 48:193-216

Chan R, Hardy WR, Dankort D, Laing MA, Muller WJ (2004) Modulation of Erbb2 signaling during development: a threshold level of Erbb2 signaling is required for development. Development 131:5551-5560

Chu CT, Everiss KD, Wikstrand CJ, Batra SK, Kung HJ, Bigner DD (1997) Receptor dimerization is not a factor in the signalling activity of a transforming variant epidermal growth factor receptor (EGFRvIII). Biochem J 324(Pt 3):855-861

Citri A, Yarden Y (2006) EGF-ERBB signalling: towards the systems level. Nat Rev Mol Cell Biol 7:505-516

Citri A, Alroy I, Lavi S, Rubin C, Xu W, Grammatikakis N, Patterson C, Neckers L, Fry DW, Yarden Y (2002) Drug-induced ubiquitylation and degradation of ErbB receptor tyrosine kinases: implications for cancer therapy. EMBO J 21:2407-2417

Citri A, Skaria KB, Yarden Y (2003) The deaf and the dumb: the biology of ErbB-2 and ErbB-3. Exp Cell Res 284:54-65

Citri A, Gan J, Mosesson Y, Vereb G, Szollosi J, Yarden Y (2004) Hsp90 restrains ErbB-2/HER2 signalling by limiting heterodimer formation. EMBO Rep 5:1165-1170

Confalonieri S, Salcini AE, Puri C, Tacchetti C, Di Fiore PP (2000) Tyrosine phosphorylation of Eps 15 is required for ligand-regulated, but not constitutive, endocytosis. J Cell Biol 150:905-912

Crosetto N, Tikkanen R, Dikic I (2005) Oncogenic breakdowns in endocytic adaptor proteins. FEBS Lett 579:3231-3238

Dankort DL, Wang Z, Blackmore V, Moran MF, Muller WJ (1997) Distinct tyrosine autophosphorylation sites negatively and positively modulate neu-mediated transformation. Mol Cell Biol 17:5410-5425

Davies GC, Ryan PE, Rahman L, Zajac-Kaye M, Lipkowitz S (2006) EGFRvIII undergoes activation-dependent downregulation mediated by the $\mathrm{Cbl}$ proteins. Oncogene 25:6497-6509 
Decker SJ (1990) Epidermal growth factor and transforming growth factor-alpha induce differential processing of the epidermal growth factor receptor. Biochem Biophys Res Commun 166:615621

Dikic I (2003) Mechanisms controlling EGF receptor endocytosis and degradation. Biochem Soc Trans 31:1178-1181

Duan L, Miura Y, Dimri M, Majumder B, Dodge IL, Reddi AL, Ghosh A, Fernandes N, Zhou P, Mullane-Robinson K, Rao N, Donoghue S, Rogers RA, Bowtell D, Naramura M, Gu H, Band V, Band H (2003) Cbl-mediated ubiquitinylation is required for lysosomal sorting of epidermal growth factor receptor but is dispensable for endocytosis. J Biol Chem 278:28950-28960

Ebner R, Derynck R (1991) Epidermal growth factor and transforming growth factor-alpha: differential intracellular routing and processing of ligand-receptor complexes. Cell Regul 2:599-612

Fallon L, Belanger CM, Corera AT, Kontogiannea M, Regan-Klapisz E, Moreau F, Voortman J, Haber M, Rouleau G, Thorarinsdottir T, Brice A, van Bergen En Henegouwen PM, Fon EA (2006) A regulated interaction with the UIM protein Eps 15 implicates parkin in EGF receptor trafficking and PI(3)K-Akt signalling. Nat Cell Biol 8:834-842

Ferguson KM, Berger MB, Mendrola JM, Cho HS, Leahy DJ, Lemmon MA (2003) EGF activates its receptor by removing interactions that autoinhibit ectodomain dimerization. Mol Cell 11:507-517

Fischer JA, Eun SH, Doolan BT (2006) Endocytosis, endosome trafficking, and the regulation of Drosophila development. Annu Rev Cell Dev Biol 22:181-206

Frederick L, Wang XY, Eley G, James CD (2000) Diversity and frequency of epidermal growth factor receptor mutations in human glioblastomas. Cancer Res 60:1383-1387

Friedman LM, Rinon A, Schechter B, Lyass L, Lavi S, Bacus SS, Sela M, Yarden Y (2005) Synergistic down-regulation of receptor tyrosine kinases by combinations of mAbs: implications for cancer immunotherapy. Proc Natl Acad Sci USA 102:1915-1920

Garcia de Palazzo IE, Adams GP, Sundareshan P, Wong AJ, Testa JR, Bigner DD, Weiner LM (1993) Expression of mutated epidermal growth factor receptor by non-small cell lung carcinomas. Cancer Res 53:3217-3220

Garrett TP, McKern NM, Lou M, Elleman TC, Adams TE, Lovrecz GO, Zhu HJ, Walker F, Frenkel MJ, Hoyne PA, Jorissen RN, Nice EC, Burgess AW, Ward CW (2002) Crystal structure of a truncated epidermal growth factor receptor extracellular domain bound to transforming growth factor alpha. Cell 110:763-773

Garrett TP, McKern NM, Lou M, Elleman TC, Adams TE, Lovrecz GO, Kofler M, Jorissen RN, Nice EC, Burgess AW, Ward CW (2003) The crystal structure of a truncated ErbB2 ectodomain reveals an active conformation, poised to interact with other ErbB receptors. Mol Cell 11:495-505

Ge H, Gong X, Tang CK (2002) Evidence of high incidence of EGFRvIII expression and coexpression with EGFR in human invasive breast cancer by laser capture microdissection and immunohistochemical analysis. Int J Cancer 98:357-361

Giebel B, Wodarz A (2006) Tumor suppressors: control of signaling by endocytosis. Curr Biol 16:R91-R92

Goetz MP, Toft DO, Ames MM, Erlichman C (2003) The Hsp90 chaperone complex as a novel target for cancer therapy. Ann Oncol 14:1169-1176

Grandal MV, Zandi R, Pedersen MW, Willumsen BM, van Deurs B, Poulsen HS (2007) EGFRvIII escapes down-regulation due to impaired internalization and sorting to lysosomes. Carcinogenesis 28:1408-1417

Graus-Porta D, Beerli RR, Daly JM, Hynes NE (1997) ErbB-2, the preferred heterodimerization partner of all ErbB receptors, is a mediator of lateral signaling. EMBO J 16:1647-1655

Grøvdal LM, Stang E, Sorkin A, Madshus IH (2004) Direct interaction of $\mathrm{Cbl}$ with pTyr 1045 of the EGF receptor (EGFR) is required to sort the EGFR to lysosomes for degradation. Exp Cell Res 300:388-395

Gruenberg J, Stenmark H (2004) The biogenesis of multivesicular endosomes. Nat Rev Mol Cell Biol 5:317-323

Haglund K, Rusten TE, Stenmark H (2007) Aberrant receptor signaling and trafficking as mechanisms in oncogenesis. Crit Rev On$\operatorname{cog}$ 13:39-74

Han W, Zhang T, Yu H, Foulke JG, Tang CK (2006) Hypophosphorylation of Residue Y1045 Leads to Defective Downregulation of EGFRvIII. Cancer Biol Ther 5:1361-1368

Harari PM, Allen GW, Bonner JA (2007) Biology of interactions: antiepidermal growth factor receptor agents. J Clin Oncol 25:40574065

Harris RC, Chung E, Coffey RJ (2003) EGF receptor ligands. Exp Cell Res 284:2-13

Haslekas C, Breen K, Pedersen KW, Johannessen LE, Stang E, Madshus IH (2005) The inhibitory effect of ErbB2 on epidermal growth factor-induced formation of clathrin-coated pits correlates with retention of epidermal growth factor receptor-ErbB2 oligomeric complexes at the plasma membrane. Mol Biol Cell 16:5832-5842

Hawryluk MJ, Keyel PA, Mishra SK, Watkins SC, Heuser JE, Traub LM (2006) Epsin 1 is a polyubiquitin-selective clathrin-associated sorting protein. Traffic 7:262-281

Hayashi T, Sakamoto S (1988) Radioimmunoassay of human epidermal growth factor-hEGF levels in human body fluids. J Pharmacobiodyn 11:146-151

Hendriks BS, Opresko LK, Wiley HS, Lauffenburger D (2003a) Quantitative analysis of HER2-mediated effects on HER2 and epidermal growth factor receptor endocytosis: distribution of homo- and heterodimers depends on relative HER2 levels. J Biol Chem 278:23343-23351

Hendriks BS, Wiley HS, Lauffenburger D (2003b) HER2-mediated effects on EGFR endosomal sorting: analysis of biophysical mechanisms. Biophys J 85:2732-2745

Hicke L (1999) Gettin' down with ubiquitin: turning off cell-surface receptors, transporters and channels. Trends Cell Biol 9:107-112

Hicke L, Riezman H (1996) Ubiquitination of a yeast plasma membrane receptor signals its ligand-stimulated endocytosis. Cell 84:277-287

Hirano S, Kawasaki M, Ura H, Kato R, Raiborg C, Stenmark H, Wakatsuki S (2006) Double-sided ubiquitin binding of Hrs-UIM in endosomal protein sorting. Nat Struct Mol Biol 13:272-277

Hommelgaard AM, Lerdrup M, van Deurs B (2004) Association with membrane protrusions makes ErbB2 an internalization-resistant receptor. Mol Biol Cell 15:1557-1567

Hommelgaard AM, Roepstorff K, Vilhardt F, Torgersen ML, Sandvig K, van Deurs B (2005) Caveolae: stable membrane domains with a potential for internalization. Traffic 6:720-724

Hong RL, Spohn WH, Hung MC (1999) Curcumin inhibits tyrosine kinase activity of p185neu and also depletes p185neu. Clin Cancer Res 5:1884-1891

Huang F, Sorkin A (2005) Growth factor receptor binding protein 2mediated recruitment of the RING domain of $\mathrm{Cbl}$ to the epidermal growth factor receptor is essential and sufficient to support receptor endocytosis. Mol Biol Cell 16:1268-1281

Huang F, Kirkpatrick D, Jiang X, Gygi S, Sorkin A (2006) Differential regulation of EGF receptor internalization and degradation by multiubiquitination within the kinase domain. Mol Cell 21:737748

Huang F, Goh LK, Sorkin A (2007) EGF receptor ubiquitination is not necessary for its internalization. Proc Natl Acad Sci USA 104:16904-16909

Hudis CA (2007) Trastuzumab-mechanism of action and use in clinical practice. N Engl J Med 357:39-51

Hurwitz E, Stancovski I, Sela M, Yarden Y (1995) Suppression and promotion of tumor growth by monoclonal antibodies to ErbB-2 
differentially correlate with cellular uptake. Proc Natl Acad Sci USA 92:3353-3357

Hynes NE, Lane HA (2005) ERBB receptors and cancer: the complexity of targeted inhibitors. Nat Rev Cancer 5:341-354

Jaramillo ML, Leon Z, Grothe S, Paul-Roc B, Abulrob A, O'Connor McCourt M (2006) Effect of the anti-receptor ligand-blocking 225 monoclonal antibody on EGF receptor endocytosis and sorting. Exp Cell Res 312:2778-2790

Jiang X, Sorkin A (2003) Epidermal growth factor receptor internalization through clathrin-coated pits requires Cbl RING finger and proline-rich domains but not receptor polyubiquitylation. Traffic 4:529-543

Jiang X, Huang F, Marusyk A, Sorkin A (2003) Grb2 regulates internalization of EGF receptors through clathrin-coated pits. Mol Biol Cell 14:858-870

Jones RB, Gordus A, Krall JA, MacBeath G (2006) A quantitative protein interaction network for the ErbB receptors using protein microarrays. Nature 439:168-174

Kamal A, Thao L, Sensintaffar J, Zhang L, Boehm MF, Fritz LC, Burrows FJ (2003) A high-affinity conformation of Hsp90 confers tumour selectivity on Hsp90 inhibitors. Nature 425:407-410

Kani K, Park E, Landgraf R (2005) The extracellular domains of ErbB3 retain high ligand binding affinity at endosome $\mathrm{pH}$ and in the locked conformation. Biochemistry 44:15842-15857

Kazazic M, Roepstorff K, Johannessen LE, Pedersen NM, van Deurs B, Stang E, Madshus IH (2006) EGF-induced activation of the EGF receptor does not trigger mobilization of caveolae. Traffic 7:1518-1527

Kirkham M, Fujita A, Chadda R, Nixon SJ, Kurzchalia TV, Sharma DK, Pagano RE, Hancock JF, Mayor S, Parton RG (2005) Ultrastructural identification of uncoated caveolin-independent early endocytic vehicles. J Cell Biol 168:465-476

Klapper LN, Vaisman N, Hurwitz E, Pinkas-Kramarski R, Yarden Y, Sela M (1997) A subclass of tumor-inhibitory monoclonal antibodies to ErbB-2/HER2 blocks crosstalk with growth factor receptors. Oncogene 14:2099-2109

Klapper LN, Waterman H, Sela M, Yarden Y (2000) Tumor-inhibitory antibodies to HER-2/ErbB-2 may act by recruiting c-Cbl and enhancing ubiquitination of HER-2. Cancer Res 60:3384-3388

Kolling R, Hollenberg CP (1994) The ABC-transporter Ste6 accumulates in the plasma membrane in a ubiquitinated form in endocytosis mutants. EMBO J 13:3261-3271

Kuan CT, Wikstrand CJ, Bigner DD (2001) EGF mutant receptor vIII as a molecular target in cancer therapy. Endocr relat cancer 8:8396

Lamaze C, Schmid SL (1995) Recruitment of epidermal growth factor receptors into coated pits requires their activated tyrosine kinase. J Cell Biol 129:47-54

Le Borgne R (2006) Regulation of Notch signalling by endocytosis and endosomal sorting. Curr Opin Cell Biol 18:213-222

Lenferink AE, Pinkas-Kramarski R, van de Poll ML, van Vugt MJ, Klapper LN, Tzahar E, Waterman H, Sela M, van Zoelen EJ, Yarden Y (1998) Differential endocytic routing of homo- and heterodimeric ErbB tyrosine kinases confers signaling superiority to receptor heterodimers. EMBO J 17:3385-3397

Lerdrup M, Hommelgaard AM, Grandal M, van Deurs B (2006) Geldanamycin stimulates internalization of ErbB2 in a proteasomedependent way. J Cell Sci 119:85-95

Lerdrup M, Bruun S, Grandal MV, Roepstorff K, Kristensen MM, Hommelgaard AM, van Deurs B (2007) Endocytic down-regulation of ErbB2 is stimulated by cleavage of its C-terminus. Mol Biol Cell 18:3656-3666

Levkowitz G, Klapper LN, Tzahar E, Freywald A, Sela M, Yarden Y (1996) Coupling of the c-Cbl protooncogene product to ErbB-1/ EGF-receptor but not to other ErbB proteins. Oncogene 12:11171125
Levkowitz G, Waterman H, Zamir E, Kam Z, Oved S, Langdon WY, Beguinot L, Geiger B, Yarden Y (1998) c-Cbl/Sli-1 regulates endocytic sorting and ubiquitination of the epidermal growth factor receptor. Genes Dev 12:3663-3674

Levkowitz G, Waterman H, Ettenberg SA, Katz M, Tsygankov AY, Alroy I, Lavi S, Iwai K, Reiss Y, Ciechanover A, Lipkowitz S, Yarden Y (1999) Ubiquitin ligase activity and tyrosine phosphorylation underlie suppression of growth factor signaling by c-Cbl/ Sli-1. Mol Cell 4:1029-1040

Levkowitz G, Oved S, Klapper LN, Harari D, Lavi S, Sela M, Yarden $\mathrm{Y}(2000) \mathrm{c}-\mathrm{Cbl}$ is a suppressor of the neu oncogene. J Biol Chem 275:35532-35539

Linggi B, Carpenter G (2006) ErbB receptors: new insights on mechanisms and biology. Trends Cell Biol 16:649-656

Longva KE, Blystad FD, Stang E, Larsen AM, Johannessen LE, Madshus IH (2002) Ubiquitination and proteasomal activity is required for transport of the EGF receptor to inner membranes of multivesicular bodies. J Cell Biol 156:843-854

Longva KE, Pedersen NM, Haslekas C, Stang E, Madshus IH (2005) Herceptin-induced inhibition of ErbB2 signaling involves reduced phosphorylation of Akt but not endocytic down-regulation of ErbB2. Int J Cancer 116:359-367

Marmor MD, Skaria KB, Yarden Y (2004) Signal transduction and oncogenesis by ErbB/HER receptors. Int $\mathrm{J}$ Radiat Oncol Biol Phys 58:903-913

Menard S, Pupa SM, Campiglio M, Tagliabue E (2003) Biologic and therapeutic role of HER2 in cancer. Oncogene 22:6570-6578

Miaczynska M, Pelkmans L, Zerial M (2004) Not just a sink: endosomes in control of signal transduction. Curr Opin Cell Biol 16:400-406

Mimnaugh EG, Chavany C, Neckers L (1996) Polyubiquitination and proteasomal degradation of the $\mathrm{p} 185 \mathrm{c}$-erbB-2 receptor protein-tyrosine kinase induced by geldanamycin. J Biol Chem 271:22796-22801

Montgomery RB, Moscatello DK, Wong AJ, Cooper JA, Stahl WL (1995) Differential modulation of mitogen-activated protein (MAP) kinase/extracellular signal-related kinase kinase and MAP kinase activities by a mutant epidermal growth factor receptor. J Biol Chem 270:30562-30566

Moscatello DK, Holgado-Madruga M, Godwin AK, Ramirez G, Gunn G, Zoltick PW, Biegel JA, Hayes RL, Wong AJ (1995) Frequent expression of a mutant epidermal growth factor receptor in multiple human tumors. Cancer Res 55:5536-5539

Moscatello DK, Montgomery RB, Sundareshan P, McDanel H, Wong MY, Wong AJ (1996) Transformational and altered signal transduction by a naturally occurring mutantEGF receptor. Oncogene 13:85-96

Moscatello DK, Holgado-Madruga M, Emlet DR, Montgomery RB, Wong AJ (1998) Constitutive Activation of Phosphatidylinositol 3-Kinase by a Naturally Occurring Mutant Epidermal Growth Factor Receptor. J Biol Chem 273:200-206

Mullin JM (2004) Epithelial barriers, compartmentation, and cancer. Sci STKE 2004:pe2-

Muthuswamy SK, Gilman M, Brugge JS (1999) Controlled dimerization of ErbB receptors provides evidence for differential signaling by homo- and heterodimers. Mol Cell Biol 19:6845-6857

Nagane M, Coufal F, Lin H, Bogler O, Cavenee WK, Huang HJ (1996) A common mutant epidermal growth factor receptor confers enhanced tumorigenicity on human glioblastoma cells by increasing proliferation and reducing apoptosis. Cancer Res 56:5079-5086

Neckers L (2002) Heat shock protein 90 is a rational molecular target in breast cancer. Breast Dis 15:53-60

Neckers L, Ivy SP (2003) Heat shock protein 90. Curr Opin Oncol 15:419-424

Nesterov A, Wiley HS, Gill GN (1995) Ligand-induced endocytosis of epidermal growth factor receptors that are defective in binding adaptor proteins. Proc Natl Acad Sci USA 92:8719-8723 
Nishikawa R, Ji X, Harmon R, Lazar C, Gill G, Cavenee W, Huang H (1994) A mutant epidermal growth factor receptor common in human glioma confers enhanced tumorigenicity. PNAS 91:77277731

Normanno N, Bianco C, De Luca A, Salomon DS (2001) The role of EGF-related peptides in tumor growth. Front Biosci 6:D685D707

Normanno N, Bianco C, Strizzi L, Mancino M, Maiello MR, De Luca A, Caponigro F, Salomon DS (2005) The ErbB receptors and their ligands in cancer: an overview. Curr Drug Targets 6:243-257

Ogiso H, Ishitani R, Nureki O, Fukai S, Yamanaka M, Kim JH, Saito K, Sakamoto A, Inoue M, Shirouzu M, Yokoyama S (2002) Crystal structure of the complex of human epidermal growth factor and receptor extracellular domains. Cell 110:775-787

Okamoto I, Kenyon LC, Emlet DR, Mori T, Sasaki J, Hirosako S, Ichikawa Y, Kishi H, Godwin AK, Yoshioka M, Suga M, Matsumoto M, Wong AJ (2003) Expression of constitutively activated EGFRvIII in non-small cell lung cancer. Cancer Sci 94:50-56

Olapade-Olaopa EO, Moscatello DK, MacKay EH, Horsburgh T, Sandhu DP, Terry TR, Wong AJ, Habib FK (2000) Evidence for the differential expression of a variant EGF receptor protein in human prostate cancer. Br J Cancer 82:186-194

Olayioye MA, Neve RM, Lane HA, Hynes NE (2000) The ErbB signaling network: receptor heterodimerization in development and cancer. EMBO J 19:3159-3167

Omerovic J, Santangelo L, Puggioni EM, Marrocco J, Dall'Armi C, Palumbo C, Belleudi F, Di ML, Frati L, Torrisi MR, Cesareni G, Gulino A, Alimandi M (2007) The E3 ligase Aip4/Itch ubiquitinates and targets ErbB-4 for degradation. FASEB J 21:28492862

Orlichenko L, Huang B, Krueger E, McNiven MA (2006) Epithelial growth factor-induced phosphorylation of caveolin 1 at tyrosine 14 stimulates caveolae formation in epithelial cells. J Biol Chem 281:4570-4579

Orth JD, Krueger EW, Weller SG, McNiven MA (2006) A novel endocytic mechanism of epidermal growth factor receptor sequestration and internalization. Cancer Res 66:3603-3610

Park JM, Yang X, Park JJ, Press OW, Press MF (1999) Assessment of novel anti-p185HER-2 monoclonal antibodies for internalizationdependent therapies. Hybridoma 18:487-495

Pedersen MW, Pedersen N, Damstrup L, Villingshoj M, Sonder SU, Rieneck K, Bovin LF, Spang-Thomsen M, Poulsen HS (2005a) Analysis of the epidermal growth factor receptor specific transcriptome: Effect of receptor expression level and an activating mutation. J Cell Biochem 96:412-427

Pedersen MW, Pedersen N, Ottesen LH, Poulsen HS (2005b) Differential response to gefitinib of cells expressing normal EGFR and the mutant EGFRvIII. Br J Cancer 93:915-923

Pelkmans L, Kartenbeck J, Helenius A (2001) Caveolar endocytosis of simian virus 40 reveals a new two-step vesicular-transport pathway to the ER. Nat Cell Biol 3:473-483

Pelkmans L, Puntener D, Helenius A (2002) Local actin polymerization and dynamin recruitment in SV40-induced internalization of caveolae. Science 296:535-539

Peschard P, Park M (2003) Escape from Cbl-mediated downregulation: a recurrent theme for oncogenic deregulation of receptor tyrosine kinases. Cancer Cell 3:519-523

Polo S, Di Fiore PP (2006) Endocytosis conducts the cell signaling orchestra. Cell 124:897-900

Polo S, Sigismund S, Faretta M, Guidi M, Capua MR, Bossi G, Chen H, De Camilli P, Di Fiore PP (2002) A single motif responsible for ubiquitin recognition and monoubiquitination in endocytic proteins. Nature 416:451-455

Polo S, Pece S, Di Fiore PP (2004) Endocytosis and cancer. Curr Opin Cell Biol 16:156-161
Qiu XB, Goldberg AL (2002) Nrdp1/FLRF is a ubiquitin ligase promoting ubiquitination and degradation of the epidermal growth factor receptor family member, ErbB3. Proc Natl Acad Sci USA 99:14843-14848

Raiborg C, Stenmark H (2002) Hrs and endocytic sorting of ubiquitinated membrane proteins. Cell Struct Funct 27:403-408

Raiborg C, Bache KG, Mehlum A, Stang E, Stenmark H (2001) Hrs recruits clathrin to early endosomes. EMBO J 20:5008-5021

Raiborg C, Malerød L, Pedersen NM, Stenmark H (2007) Differential functions of Hrs and ESCRT proteins in endocytic membrane trafficking. Exp Cell Res (in press)

Reutens AT, Begley CG (2002) Endophilin-1: a multifunctional protein. Int J Biochem Cell Biol 34:1173-1177

Revillion F, Lhotellier V, Hornez L, Bonneterre J, Peyrat JP (2008) ErbB/HER ligands in human breast cancer, and relationships with their receptors, the bio-pathological features and prognosis. Ann Oncol 19:73-80

Rubin I, Yarden Y (2001) The basic biology of HER2. Ann Oncol 12(Suppl 1):S3-S8

Sachse M, Urbe S, Oorschot V, Strous GJ, Klumperman J (2002) Bilayered clathrin coats on endosomal vacuoles are involved in protein sorting toward lysosomes. Mol Biol Cell 13:1313-1328

Salomon DS, Brandt R, Ciardiello F, Normanno N (1995) Epidermal growth factor-related peptides and their receptors in human malignancies. Crit Rev Oncol Hematol 19:183-232

Sandvig K, Torgersen ML, Raa HA, van Deurs B (2008) Clathrin-independent endocytosis: from nonexisting to an extreme degree of complexity. Histochem Cell Biol (in press)

Sawai A, Chandarlapaty S, Greulich H, Gonen M, Ye Q, Arteaga CL, Sellers W, Rosen N, Solit DB (2008) Inhibition of Hsp90 downregulates mutant epidermal growth factor receptor (EGFR) expression and sensitizes EGFR mutant tumors to paclitaxel. Cancer Res 68:589-596

Sigismund S, Woelk T, Puri C, Maspero E, Tacchetti C, Transidico P, Di Fiore PP, Polo S (2005) Clathrin-independent endocytosis of ubiquitinated cargos. Proc Natl Acad Sci USA 102:2760-2765

Solit DB, Chiosis G (2008) Development and application of Hsp90 inhibitors. Drug Discov Today 13:38-43

Sorkin A, Carpenter G (1993) Interaction of activated EGF receptors with coated pit adaptins. Science 261:612-615

Sorkin A, von Zastrow M (2002) Signal transduction and endocytosis: close encounters of many kinds. Nat Rev Mol Cell Biol 3:600614

Sorkin A, McKinsey T, Shih W, Kirchhausen T, Carpenter G (1995) Stoichiometric interaction of the epidermal growth factor receptor with the clathrin-associated protein complex AP-2. J Biol Chem 270:619-625

Soubeyran P, Kowanetz K, Szymkiewicz I, Langdon WY, Dikic I (2002) Cbl-CIN85-endophilin complex mediates ligand-induced downregulation of EGF receptors. Nature 416:183-187

Stang E, Blystad FD, Kazazic M, Bertelsen V, Brodahl T, Raiborg C, Stenmark H, Madshus IH (2004) Cbl-dependent ubiquitination is required for progression of EGF receptors into clathrin-coated pits. Mol Biol Cell 15:3591-3604

Stern KA, Place TL, Lill NL (2007) EGF and amphiregulin differentially regulate $\mathrm{Cbl}$ recruitment to endosomes and EGF receptor fate. Biochem $\mathrm{J}$ (in press)

Sugawa N, Ekstrand A, James C, Collins V (1990) Identical splicing of aberrant epidermal growth factor receptor transcripts from amplified rearranged genes in human glioblastomas. Proc Natl Acad Sci USA 87:8602-8606

Sunada H, Magun BE, Mendelsohn J, MacLeod CL (1986) Monoclonal antibody against epidermal growth factor receptor is internalized without stimulating receptor phosphorylation. Proc Natl Acad Sci USA 83:3825-3829 
Tang CK, Gong XQ, Moscatello DK, Wong AJ, Lippman ME (2000) Epidermal growth factor receptor vIII enhances tumorigenicity in human breast cancer. Cancer Res 60:3081-3087

Thomsen P, Roepstorff K, Stahlhut M, van Deurs B (2002) Caveolae are highly immobile plasma membrane microdomains, which are not involved in constitutive endocytic trafficking. Mol Biol Cell 13:238-250

Tikhomirov O, Carpenter G (2000) Geldanamycin induces ErbB-2 degradation by proteolytic fragmentation. J Biol Chem 275:26625-26631

Tikhomirov O, Carpenter G (2001) Caspase-dependent cleavage of ErbB-2 by geldanamycin and staurosporin. J Biol Chem 276:33675-33680

Tikhomirov O, Carpenter G (2003) Identification of ErbB-2 kinase domain motifs required for geldanamycin-induced degradation. Cancer Res 63:39-43

Torrisi MR, Lotti LV, Belleudi F, Gradini R, Salcini AE, Confalonieri S, Pelicci PG, Di Fiore PP (1999) Eps15 is recruited to the plasma membrane upon epidermal growth factor receptor activation and localizes to components of the endocytic pathway during receptor internalization. Mol Biol Cell 10:417-434

Tzahar E, Waterman H, Chen X, Levkowitz G, Karunagaran D, Lavi S, Ratzkin BJ, Yarden Y (1996) A hierarchical network of interreceptor interactions determines signal transduction by Neu differentiation factor/neuregulin and epidermal growth factor. Mol Cell Biol 16:5276-5287

Vastag B (2006) HSP-90 inhibitors promise to complement cancer therapies. Nat Biotechnol 24:1307

Wang Z, Zhang L, Yeung TK, Chen X (1999) Endocytosis deficiency of epidermal growth factor (EGF) receptor-ErbB2 heterodimers in response to EGF stimulation. Mol Biol Cell 10:1621-1636

Warren CM, Landgraf R (2006) Signaling through ERBB receptors: multiple layers of diversity and control. Cell Signal 18:923-933

Waterman H, Sabanai I, Geiger B, Yarden Y (1998) Alternative intracellular routing of ErbB receptors may determine signaling potency. J Biol Chem 273:13819-13827

Waterman H, Alroy I, Strano S, Seger R, Yarden Y (1999) The C-terminus of the kinase-defective neuregulin receptor ErbB-3 confers mitogenic superiority and dictates endocytic routing. EMBO J 18:3348-3358

Waterman H, Katz M, Rubin C, Shtiegman K, Lavi S, Elson A, Jovin T, Yarden Y (2002) A mutant EGF-receptor defective in ubiquitylation and endocytosis unveils a role for Grb2 in negative signaling. EMBO J 21:303-313

Way TD, Kao MC, Lin JK (2004) Apigenin induces apoptosis through proteasomal degradation of HER2/neu in HER2/neu-overexpressing breast cancer cells via the phosphatidylinositol 3-kinase/Akt-dependent pathway. J Biol Chem 279:4479-4489

Whitesell L, Lindquist SL (2005) HSP90 and the chaperoning of cancer. Nat Rev Cancer 5:761-772

Williams RL, Urbe S (2007) The emerging shape of the ESCRT machinery. Nat Rev Mol Cell Biol 8:355-368

Worthylake R, Opresko LK, Wiley HS (1999) ErbB-2 amplification inhibits down-regulation and induces constitutive activation of both ErbB-2 and epidermal growth factor receptors. J Biol Chem 274:8865-8874

Xu W, Mimnaugh E, Rosser MF, Nicchitta C, Marcu M, Yarden Y, Neckers L (2001) Sensitivity of mature Erbb2 to geldanamycin is conferred by its kinase domain and is mediated by the chaperone protein Hsp90. J Biol Chem 276:3702-3708

Xu W, Marcu M, Yuan X, Mimnaugh E, Patterson C, Neckers L (2002) Chaperone-dependent E3 ubiquitin ligase CHIP mediates a degradative pathway for c-ErbB2/Neu. Proc Natl Acad Sci USA 99:12847-12852

Yarden Y (2001) Biology of HER2 and its importance in breast cancer. Oncology 61(Suppl 2):1-13

Zandi R, Larsen AB, Andersen P, Stockhausen MT, Poulsen HS (2007) Mechanisms for oncogenic activation of the epidermal growth factor receptor. Cell Signal 19:2013-2023

Zheng FF, Kuduk SD, Chiosis G, Munster PN, Sepp-Lorenzino L, Danishefsky SJ, Rosen N (2000) Identification of a geldanamycin dimer that induces the selective degradation of HER-family tyrosine kinases. Cancer Res 60:2090-2094

Zhou P, Fernandes N, Dodge IL, Reddi AL, Rao N, Safran H, DiPetrillo TA, Wazer DE, Band V, Band H (2003) ErbB2 degradation mediated by the co-chaperone protein CHIP. J Biol Chem 278:13829-13837 